\title{
Anthropometric Measures in the Prediction of High Fat Percentage in Female Adolescents
}

\author{
Nilviane Pires Silva Sousa ${ }^{1,2,3}$, Anne Caroline Silva e Silva ${ }^{4}$, Carlos Magno Sousa \\ Junior $^{2}$, Marta de Oliveira Barreiros ${ }^{2}$, Sally Cristina Moutinho Monteiro ${ }^{3}$, \\ Allan Kardec Barros ${ }^{1,2}$ \\ ${ }^{1}$ Post-Graduate Program in Biotechnology, Center for Biological Sciences and Health, Federal \\ University of Maranhão (UFMA), São Luís-MA, Brazil. \\ ${ }^{2}$ Federal University of Maranhão (UFMA), Department of Electrical Engineering, Laboratory for \\ Biological Information Processing (PIB), São Luís-MA, Brazil \\ ${ }^{3}$ Post-Graduate Program in Adult and Child Health, Center for Biological Sciences and Health, \\ Federal University of Maranhão (UFMA), São Luís-MA, Brazil \\ ${ }^{4}$ Graduate in Nutrition, Santa Terezinha College, São Luís-MA.
}

\begin{abstract}
:
Objective: This study aimed to evaluate the predictive power of anthropometric indices for the diagnosis of high fat mass in female adolescents.

Subjects/Methods: This is a cross-sectional study with a sample of 233 students female, aged 10-19 years, from 16 public schools of São Luís (Maranhão State, Brazil). The following indicators were assessed: body mass index (BMI), waist circumference (WC), conicity index (C-index), and the waist-to-height ratio (WHtR). The percentage of body fat was estimated using a bioimpedance device quadruple model. The cut-off points used in the excess 10 body fat classification were established by Lohman et al., was used as the reference method in the analysis Curve ROC. Descriptive analyses, Student's t test for independent samples, Mann Whitney $U$ test and Person correlation coefficient were used for data analysis.
\end{abstract}

Results: BMI presented the largest areas under the ROC curve $($ ROC area $=0.87)$ in the prediction of excess body fat. The BMI anthropometric indicator showed the highest correlation with body fat percentage $(r=0.69)$ compared to the other studied indicators.

Conclusion: In this context, the BMI proved to be the best predictor of high body fat in the evaluated sample.

Keywords: Anthropometry, body fat, Obesity, Adolescents.

Abbreviations: body mass index -BMI, Waist circumference - WC, Conicity index - C-index, Waist-to-height ratio - WHtR

\section{INTRODUCTION}

Obesity results from a chronic imbalance between caloric intake and energy expenditure, the prevalence of obesity has been increasing worldwide for the past 30 years, possibly because of increased caloric intake and decreased physical activity. ${ }^{[1]}$ The increasing prevalence of pediatric obesity may be problematic because not only it increases the prevalence of, but also it can advance the age of onset of obesity-related chronic diseases such as type 2 diabetes and cardiovascular diseases. ${ }^{[1]}$ Anthropometry is widely used in the assessment of children and adolescent nutritional status. It shows sing a number of advantages: it is non-invasive, it is easy to perform at low cost, and it can be applied in a large number of individuals, when compared to other methods such as hydrostatic weighing and dual x-ray absorptiometry -DEXA. ${ }^{[2]}$ The body mass index (BMI) is one of the most used anthropometric indicators because it is safe, easy to apply at a low cost and identifies the nutritional status of children and adolescents. ${ }^{[3]}$ It is also used as a method for obesity screening and health risk assessment. ${ }^{[4]}$ It is recognized as a predictor of morbidity and mortality of several chronic non-communicable diseases (CND) ${ }^{[5]}$ and in epidemiological studies, it is used to identify general fat. ${ }^{[6]}$ Waist circumference (WC) is an indicator of abdominal adiposity, which is often 
associated with the same obesity-related risk factors. ${ }^{[7]}$ It can be used as an instrument to identify adolescents who are more likely to have cardiovascular risk factors. ${ }^{[8]}$ The $\mathrm{c}$ index is able to evaluate the fat located in the central part of the body, thus becoming a measure which is independent of the circumference of the hip, an important aspect in the case of adolescents, due to the bodily variations typical of the pubertal phase, besides being an Low cost anthropometric tool of and easy to standardize. ${ }^{[9]}$ The Waist-to-Height Ratio (WHtR) is determined by the division of the WC $(\mathrm{cm})$ by height $(\mathrm{cm})$, the reasoning is that, for a certain stature, there is an acceptable amount of fat stored in the upper body ${ }^{[10]}$, that is, it considers the proportion of central fat by height of the individual. It has been successfully tested in the identification of the main cardiovascular risk factors in pediatric population. Anthropometric indicators emerge as simple, easily accessible, and non-invasive measures that can diagnose obesity. Thus, the purpose of this study was to assess the predictive power of anthropometric indices for the diagnosis of high fat mass in female adolescents.

\section{MeTHODS}

\subsection{Subjects}

This research was conducted from 2011 to 2014 . The sample size was determined by proportion ${ }^{[11]}$ based on a prevalence of overweight in female adolescents of $4.0 \%{ }^{[12]}$, a suggested outcome prevalence of $10 \%$, tolerable error of 5\% (type I error), and power of the test of $90 \%$ (type II error), reaching 184 individuals. With an additional $10 \%$ for possible losses or refusals resulted in a sample of 202 female adolescents. The sample was obtained from a school population of 16 schools of the municipal, state, and federal education systems in the city of São Luís, located in the State of Maranhão, Brazil. The schools were randomly chosen and the final sample consisted of 233 female adolescents aged $10-19$ years.

The following exclusion criteria were used: pregnant or nursing adolescents, those using contraceptive pills or who had not reached menarche, and those with a physical disability that prevented or hindered measurements. This study was approved by the Human Research Ethics Committee of the University Hospital of the Federal University of Maranhão (Hospital Universitário da Universidade Federal do Maranhão-HUUFMA), protocol number 251/11.

\subsection{Measurements}

The measurement of all variables was performed by trained staff to use calibrated equipment. Anthropometric measurements including weight, height, and waist measurements were obtained using standardized techniques by well-trained researchers. ${ }^{[13]}$ All measurements were performed in duplicate, with the mean being considered for data analysis.

Weight was measured using a digital scale (Seca ${ }^{\circledR} 803$, Hamburg, Germany) with a $0.1 \mathrm{~kg}$ resolution, height was measured using a portable vertical stadiometer (Seca ${ }^{\circledR} 213$, Hamburg, Germany) with a 1 $\mathrm{mm}$ resolution, and waist circumference was measured using inextensible anthropometric tape with $0.1 \mathrm{~cm}$ resolution (Seca ${ }^{\circledR} 201$, Hamburg, Germany) at the smallest horizontal girth between the costal margins and the iliac crest at minimal respiration.

BMI was calculated for each participant as a ratio of weight divided by height squared $\left(\mathrm{kg} / \mathrm{m}^{2}\right)$ and the waist-to-height ratio $(\mathrm{WHtR})$ was calculated by the formula ${ }^{[14]}$ : [WC $(\mathrm{cm}) /$ height $\left.(\mathrm{cm})\right]$. The conicity index (C-index) was determined by measuring weight, height, and $\mathrm{WC}$, and applying the equation ${ }^{[15]}$ : $\mathrm{C}-$ index $=\mathrm{WC}(\mathrm{cm}) / 0.109 \sqrt{\text { Body weight }(\mathrm{kg}) / \operatorname{Height}(\mathrm{m})}$.

The percentage of body fat, percentage lean mass and percentage water was estimated using a bioimpedance device quadruple model (Maltron ${ }^{\circledR}$, BF-906, Cardiomed/Brazil) according to the protocols established in the instrument manual.

The cut-off points used for excess body fat classification were established by Lohman et al. $(1988)^{[13]}$, where values above $25 \%$ for girls classified adolescents with excess body fat. This method was also used as a reference in the ROC curve analysis.

\subsection{Statistical Analysis}

The SPSS version 19.0 (Statistical Package for the Social Sciences, Chicago, IL, USA) was used for database and statistical analysis. The results were expressed as mean, median and standard deviation (mean or median $\pm \mathrm{SD}$ ). Normal distribution for the data was tested using the Kolmogorov-Smirnov 
test. The assessment of the means between the two groups was carried out with the Student's t-test for two independent samples, in the case of normally distributed variables, or Mann-Whitney U-test for two independent samples if variables were not normally distributed. The ROC curve analysis was performed to evaluate the diagnostic performance of BMI, WC, C-index, and WHtR in detecting fat body. The accuracy refers to the ability of BMI, WC, C-index, and WHtR to discriminate adolescents with excess body fat from those without excess body fat. Areas under the ROC curve, p-value and confidence intervals were determined. The Pearson correlation coefficient was used to assess associations between the anthropometric indexes (BMI, WC, HCR, and C-index) and body fat percentage. For all tests, statistical significance was established at $\mathrm{p}$-value $<0.05$.

\section{ReSUlts}

Mean, medians and standard deviation of the anthropometric variables of the studied sample are described in Table 1. Excess weight adolescents (Overweight + Obese) showed higher values of age, BMI, WC, C index, WHtR, lean mass, water and body fat percentage all with $\mathrm{p}<0.001$, in comparison to eutrophic adolescents. All anthropometric indicators were able to predict the high body fat in the sample (Table 2), but the index with the highest area under the ROC curve was the BMI (ROC area = 0.87).The Pearson correlation coefficients between the anthropometric variables and body fat percentage are shown in Table 3. The BMI anthropometric indicator showed the highest correlation with body fat percentage $(\mathrm{r}=0.69)$ compared to the other studied indicators.

Table1. Characteristics of participants stratified by BMI

\begin{tabular}{|l|c|c|c|}
\hline Variables & $\begin{array}{c}\text { Eutrophic } \\
(\mathrm{n}=134)\end{array}$ & $\begin{array}{c}\text { Excess weight } \\
(\mathrm{n}=99)\end{array}$ & p-value \\
\hline Age $(\text { years })^{\dagger \mathrm{b}}$ & $15.10 \pm 1.97$ & $13.40 \pm 2.36$ & $<0.001$ \\
\hline BMI $\left(\mathrm{kg} / \mathrm{m}^{2}\right)^{\dagger \mathrm{b}}$ & $19.61 \pm 2.13$ & $25.41 \pm 3.15$ & $<0.001$ \\
\hline $\mathrm{WC}(\mathrm{cm})^{\dagger \mathrm{b}}$ & $65.50 \pm 6.68$ & $80.00 \pm 9.50$ & $<0.001$ \\
\hline $\mathrm{C} \mathrm{Index}^{*}{ }^{\mathrm{a}}$ & $0.98 \pm 0.08$ & $1.04 \pm 0.09$ & $<0.001$ \\
\hline $\mathrm{WHtR}^{\dagger \mathrm{b}}$ & $0.42 \pm 0.04$ & $0.51 \pm 0.06$ & $<0.001$ \\
\hline$\% \mathrm{BF}^{* a}$ & $25.02 \pm 6.8$ & $34.11 \pm 5.67$ & $<0.001$ \\
\hline$\% \mathrm{LM}^{* \mathrm{a}}$ & $36.20 \pm 5.64$ & $42.39 \pm 6.35$ & $<0.001$ \\
\hline$\% \mathrm{~W}^{\dagger \mathrm{b}}$ & $100.00 \pm 11.15$ & $110.00 \pm 11.88$ & $<0.001$ \\
\hline
\end{tabular}

Acronyms: BMI- body mass index; WC-waist circumference, CI- conicity index; WHtR- waist-to-height ratio; $\% B F$ - percentage body fat; \%LM - percentage lean mass; $\% W$ - percentage water. "Student's $t$ test for independent variables; ${ }^{\dagger}$ Mann-Whitney $U$ test; ${ }^{a}$ values described as mean $\pm S D$ (standard deviation); ${ }^{b}$ values described as median $\pm S D$ (standard deviation).

Table2. Area under the ROC curve, sensitivity and specificity of cutoff points according to anthropometric indexes

\begin{tabular}{|l|l|l|}
\hline Anthropometric index & Curve ROC (CI 95\%) & p-value \\
\hline BMI $\left(\mathrm{kg} / \mathrm{m}^{2}\right)$ & $0.87(0.82-0.92)^{*}$ & $<0.001$ \\
\hline WC $(\mathrm{cm})$ & $0.83(0.78-0.89)^{*}$ & $<0.001$ \\
\hline C Index & $0.68(0.60-0.75)^{*}$ & $<0.001$ \\
\hline WHtR & $0.83(0.77-0.88)^{*}$ & $<0.001$ \\
\hline
\end{tabular}

Abbreviations: C195\%, confidence interval; BMI, body mass index; WC, waist circumference; C Index, conicity index; WHtR, waist-to-height ratio. *: area under the ROC curve demonstrating discriminatory power for body fat (lower limit of CI95\%>0.50).

Table3. Pearson correlation coefficients between anthropometric parameters and body fat percentage

\begin{tabular}{|c|c|}
\hline Variables & $\% \mathrm{BF}$ \\
\hline $\mathrm{IMC}\left(\mathrm{kg} / \mathrm{m}^{2}\right)$ & $0.69^{* *}$ \\
\hline $\mathrm{WC}(\mathrm{cm})$ & $0.61^{* * *}$ \\
\hline $\mathrm{C}-\mathrm{index}$ & $0.31^{* *}$ \\
\hline WHtR & $0.62^{* *}$ \\
\hline
\end{tabular}

*** $p<0.01$

\section{DISCUSSION}

The prevalence of overweight and obesity has to been increasing in the last decades and is related to the appearance of several comorbidities such as cardiovascular diseases and metabolic disorders (insulinemia, dyslipidemia, among others). There is evidence that $20 \%$ of obese children before 
reaching age five tend to become obese adults and when obesity reaches the adolescent group, the proportion increase to $80 \% .{ }^{[16]}$ Before this alarming situation, the need for research might and actions aimed at changing this panorama is reinforced. ${ }^{[16]}$

All indicators were able to predict the high body fat (area under the ROC curve $>0.5$ ) in the sample (Table 3). However, the BMI showed the largest area under the ROC curve (ROC area $=0.87$ ), proving to be the best discriminator of body fat.

Body mass index (BMI) is the index most used to evaluate the nutritional status of adolescents, due to its low cost, simplicity and high reproducibility. It is also recommended by the World Health Organization for the evaluation of nutritional status in children and adolescents. ${ }^{[6,17,18,19]}$

In the present study, WC and WHtR showed a similar ability to discriminate the percentage of high fat in the adolescent. Studies such as that performed with 1,268 adolescents, aged 15-17 years in southern Brazil found that the waist circumference (WC) and WHtR have sufficient similarity to discriminate body fat corroborating our results. ${ }^{[2]}$ The WHtR and WC are considered useful to identify, among overweight children and adolescents, those with high metabolic and cardiovascular risk that can be used to screen groups of risks, along with BMI.

The $\mathrm{C}$ index in relation to the other parameters evaluated was not considered a good predictor of high body fat. Pereira e Serrano et al. (2015) ${ }^{[20]}$, in a study performed with girls aged 14-19, observed that $\mathrm{C}$ index was not a good indicator of body mass and total body fat. Pelegrini et al. $(2015)^{[2]}$ found that $\mathrm{C}$ index had a lower ability to discriminate body fat in adolescents. The $\mathrm{C}$ index may not be a good anthropometric indicator of fat in the trunk in children and adolescents, probably because the relationships between the measures are not good indicators of obesity. ${ }^{[20]}$ Furthermore, the distribution of body fat differs between genders. The reserve of adipose tissue in women to be accumulates predominantly in the gluteo-femoral region, while in men in the central region. ${ }^{[21]}$ these changes in body composition and distribution of the fat mass (greater in females) and muscle mass (greater in males) occur during and after pubertal spurt. ${ }^{[22]}$

These are the result of the reactivation of the neurohormonal mechanisms of the hypothalamicpituitary-gonadal axis, which begins with the increase of the gonadotrophic, adrenal and thyroid hormones and proceeds with the production of androgens by the testes and estrogens / progesterone by the ovaries. ${ }^{[22]}$

The use of valid measures in the evaluation of body composition and the fat distribution pattern is necessary in population studies and clinical practice, in order to early identify individuals at risk of developing diseases and to assist in the prevention / treatment of obesity. ${ }^{[20]}$

\section{Conclusion}

In this context, the BMI showed a higher correlation with percentage of body fat for this population. It can be used as a low cost screening method and good reproducibility in the assessment of the nutritional status of female adolescents.

\section{ACKNOWLEDGMENTS}

The authors would like to thank the School Board of Directors, students and their parents or next of kin for their participation in the study. This study was supported by grants from the Fundação de Amparo à Pesquisa e ao Desenvolvimento Científico e Tecnológico do Estado do Maranhão (FAPEMA, ProcessBM No. 03347/14).

\section{REFERENCES}

[1] Yoo E-G.(2016). Waist-to-height ratio as a screening tool for obesity and cardiometabolicrisk. Korean J Pediatr.59(11):425431. doi: 10.3345/kjp.2016.59.11.425

[2] Pelegrini A., Silva D.A.S., Silva J.M.F.L., Grigollo L. andPetroski E.L. (2015). Anthropometric indicators of obesity in the prediction of high body fat in adolescents. Rev Paul Pediatr. 33: 5662. doi: http://dx.doi.org/10.1016/j.rpped.2014.06.007.

[3] Montarroyos E.C.L., Costa K.R.L. and Fortes R.C. (2013).Anthropometry and its importance in the nutriotional of schoolchildren.Com. Ciências Saúde. 24 (1); 21-26.

[4] Chung H.I., Park S., Park J.M., Yoo E.G. (2016).Waist-to-Height Ratio as an Index for Cardiometabolic Risk in Adolescents: Results from the 1998-2008 KNHANES. Yonsei Med J. 57: 658-663. 
[5] Mota J.F., Rinaldi A.E.M., Pereira A.F., Orsatti F.L., Burini R.C. (2011).Anthropometric indicators as risk markers for metabolic abnormalities. Ciências e Saúde Coletiva, 16 (9): 3901 3908.doi:http://dx.doi.org/10.1590/S1413-81232011001000026

[6] Beck C.C., Lopes A.S., Pitanga F.J.G. (2011). Anthropometric indexes of overweight and obesity as predictores of lipid changes in adolescentes.Rev Paul Pediatr 29 (1); 46-53.doi: http://dx.doi.org/10.1590/S0103-05822011000100008

[7] Oliveira A.V., Costa A.C.P.J., Pascoal L.V. et al. (2014). Correlação entre indicadores antropométricos e pressão arterial de adolescentes. Texto Contexto Enferm. 23(4):995-1003.

[8] Bergamann G.G., Bergamann M.L.A., Moreira.R.B., Pinheiro E.S. et al.(2011).Overweight and obesity in childhood and adolescence: possibility of measurements and reflections about evaluation proposals.Revista Brasileira de Atividade Física \& Saúde, 16 (11). 62-69. doi: http://dx.doi.org/10.12820/RBAFS.V.16N1P62-69

[9] Marques M. P., Lyra C. O., Lima, S. C. V. C., Pinheiro L. G. B., Azevedo P. R. M. et al. (2011). Coronary risk in adolescents as estimated by the Conicity index. Nutrire:rev. Soc. Bras. Alim.Nutr.= J. Brazilian Soc. Food Nutr. 36 (1): 99-109.

[10] Magalhães E.I.S., Sant'Ana L.F.R., Priore S.E., Franceschini S.C.C. (2014).Waist circumference, waist/height ratio, and neck circumference as parameters of central obesity assessment in children. Rev Paul Pediatr. 32(3):273-82. doi:http://dx.doi.org/10.1590/01030582201432320

[11] Lwanga S.K.,Lemeshow S. (1991) Sample size determination in health studies: a practical manual. Geneva, World Health Organization.

[12] PESQUISA DE ORÇAMENTOS FAMILIARES (POF 2008-2009). (2010). Antropometria e estado nutricional de crianças, adolescentes e adultos no Brasil. Rio de Janeiro: IBGE.

[13] Lohman T.G., Roche A.F., Martorell R. (1988) Anthropometric Standardization Reference Manual. Champaign, Illinois: Human Kinetics.

[14] Ashwell M., Hsieh S.D. (2005). Six reasons why the waist-to-height ratio is a rapid and effective global indicator for health risks of obesity and how its use could simplify the international public health message on obesity. Int J Food Sci Nutr; 56: 303-307. doi:http://dx.doi.org/10.1080/ 09637480500195066

[15] Valdez RA. (1991). Simple Model-Based Index of abdominal adiposity.J ClinEpidemiol. 333 44: 955-956.

[16] Souza G.S., Quadros T.M.B.,Gordia T.B. et al.(2015). Literature review on anthropometric extremes in children and adolescents: prevalence, health risks and associated socio demographic factors. Rev. de Atenção à Saúde, v. 13, n. 45, p. 102-11.

[17] Conde W.L., Monteiro C.A. (2006). Boby mass index cutoff points for evaluation of nutritional status in Brazilian children and adolescents. J Pediatr. 82:266-272.

[18] Farias Júnior J.C., Konrad L.M.,Rabacow F.M. et al. (2009). Sensitivity and specificity of criteria for classifying body mass index in adolescents. Rev Saúde Pública, 43:53-59.

[19] PinhoL., et al. (2014). Associated factors of overweight in adolescents from public schools in Northern Minas Gerais State, Brazil. Rev Paul Pediatr, 32(2); 237-243.

[20] Pereira P.F., Serrano H.M.S., Carvalho G.Q., Ribeiro S.M.R., et al. (2015). Measurements of body fat distribution: assessment of collinearity with body mass, adiposity and height in female adolescentes.Rev Paul Pediatr. 33(1):63-71. doi:http://dx.doi.org/10.1016/j.rpped.2014.11.011

[21] Harwood J.H. (2012). The adipocyte as an endocrine organ in the regulation of metabolic homeostasis. Neuropharmacology, 63:57-75. H. doi:http://dx.doi.org/10.1016/j.neuropharm. 2011.12.010

[22] Eisenstein E., Coelho K.S.C., Coelho S.C., Coelho M.A.S.C. (2000). Nutrition in adolescence. Jornal de Pediatria, 76(3): 263-274. 